\title{
EVALUATION OF THE CALORIFIC VALUES OF WASTES FROM SOME TROPICAL WOOD SPECIES
}

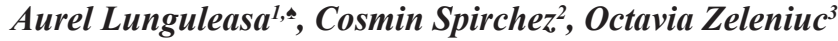

\begin{abstract}
The paper aims to analyze and classified some exotic wood species from tropical Africa, on regard to calorific features, in order to view the ability of their biomass to be a solid, natural and renewable fuel. The calorific values of wood wastes of eight tropical species were determined using an oxygen bomb calorimeter. The tested specimens were conditioned at a moisture content of $10 \%, 20 \%$, and $50 \%$. The influence of moisture content on calorific value and density, heat release rate and calorific efficiency were also analyzed. The biggest high calorific value and low calorific value were obtained by Guaiac and Rose species $(21200-20700 \mathrm{~kJ} / \mathrm{kg})$. Acajou had the lowest values of high calorific value and low calorific value (18929 and $18456 \mathrm{~kJ} / \mathrm{kg}$, respectively). For higher wood density (Guaiac) the higher calorific density was obtained. The moisture content of specimens had negatively influenced the calorific efficiency and rate of energy release. The ash content was below 4\% with highest values for Guaiac $(3,6 \%)$ and the lowest for Acajou $(0,5 \%)$. The results showed that the analyzed tropical wood species had a forest calorific capacity with 23 $47 \%$ higher than of European beech, thus can be considered a good potential as renewable energy resources.
\end{abstract}

Keywords: Ash content, calorific value, calorific density, energy release, tropical specie, wood biomass.

\section{INTRODUCTION}

Wood biomass represents a great potential for the energy production and consumption all over of the world. There are many wood biomass sources (Adam et al. 2018, Barro et al. 2020, Ozyuguran et al. 2018, Perez-Arevalo and Velaszquez-Marti 2018), starting with forestry operations, forest residues, byproducts from wood processing, wood from demolition sites and even municipal wastes. The wood industry provides a wide range of wood wastes from primary processing of logs to veneers, plywood, panelboards, Oriented Strand Board (OSB), Medium Density Fiberboard (Adam et al. 2018) and furniture manufacturing. Wood and solid biomass accounted about $69 \%$ for all energy consumption on 2018 in Europe (AEBIOM 2019) as it can be seen in Figure 1. The interest in the use of the renewable energy has been growing fast in the last years, due to the problems of global warming and continued depletion of fossil fuels. Wooden biomass has also a great advantage because it can be used individually, or in combination with fossil coal (Adam et al. 2018).

Traditional biomass materials used for energy production include fuelwood, charcoal, and crop residues; these play an important role in many developing countries. In recent years, policies and programs have been developed to promote the use of renewable energy sources (AEBIOM 2019), the energy based on forest biomass being considered a reliable alternative. The potential to use the wood wastes from mills to produce electricity is significant. For instance $60 \%$ from electricity consumed in Gabon, $12 \%$ in Nigeria and $8 \%$ in Malaysia are obtained from wood waste (AEBIOM 2019). The volume of wood residues left from harvesting operations in tropical forests is three to six times that generated at mills. Tropical and sub-tropical species grows in zone with warm and moist climate, occupying $7 \%$ from global surface of globe, and $44 \%$ from the global forest area

\footnotetext{
'Professor at Transilvania University of Brasov, Faculty of Wood Engineering, Brasov Romania.

${ }^{2}$ Assistant professor at Transilvania University of Brasov, Faculty of Wood Engineering, Brasov, Romania.

${ }^{3}$ Associate professor at Transilvania University of Brasov, Faculty of Wood Engineering, Brasov, Romania.

•Corresponding author: lunga@unitbv.ro
}

Received: 11.04.2018 Accepted: 20.02.2020 
(Jasinskas et al. 2020), being an important source of biomass. It is estimated that more than $40 \%$ of the oxygen produced in the world comes from these vegetal areas, which have undergone large-scale desertification in recent years, rapidly reducing this ecosystem around the world (Park et al. 2020, Adam et al. 2018).

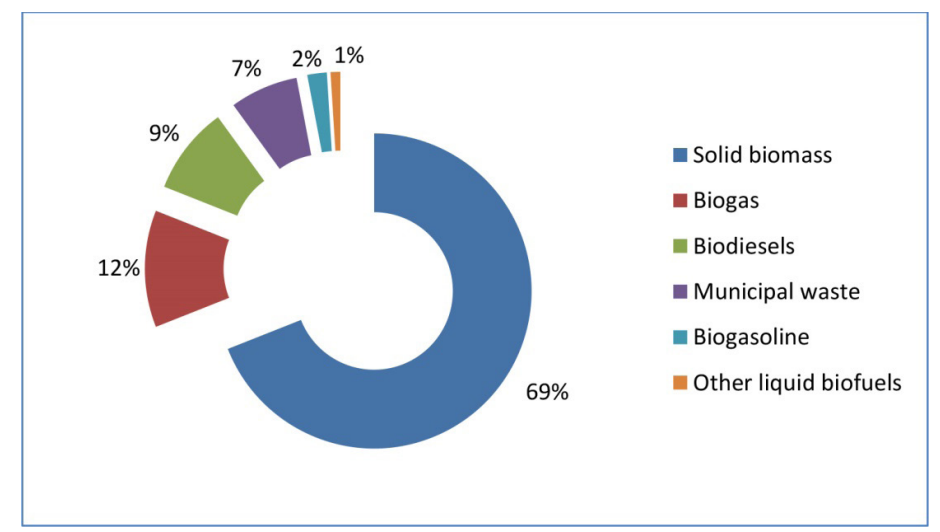

Figure 1: Energy consumption from biomass and bio-waste in Europe (AEBIOM 2019).

Generally is estimated that the wood volume of these species is higher than the temperate species but the overall wood density is lower due to the growing conditions (high air temperature and relative humidity), especially soil humidity (Jasinskas et al. 2020, Park et al. 2020). The macroscopic structure shows the weak differences occurred in the growing areas during one year due to the rainy and dry season (Figure 2).

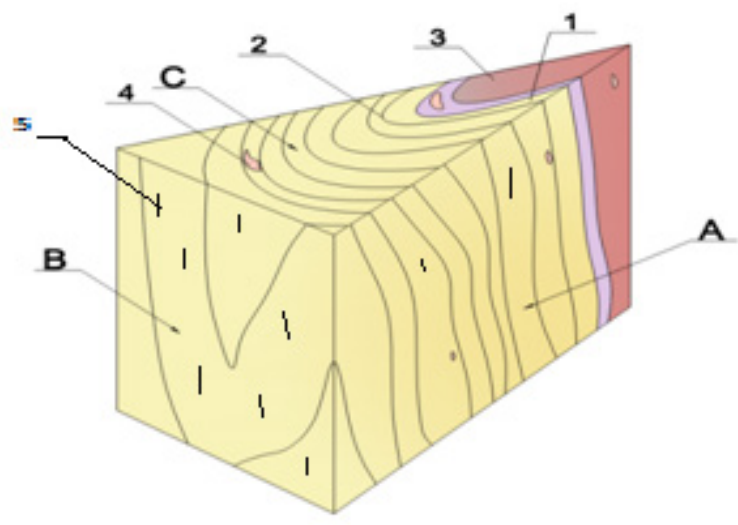

Figure 2: Macroscopic structure of tropical wood species: A-radial section; B-tangential section; C-cross section; 1-sapwood; 2-growth ring; 3-heartwood; 4-medullary stain; 5-pores.

Nowadays, the estimate number of tropical wood species including gymnosperms and angiosperms with diameters at breast height ( $\mathrm{dbh}) \geq 10 \mathrm{~cm}$ is around 50000 (AEBIOM 2019). They are spread in different tropical areas such as: South and Central America near the Amazon River, in Africa near the Congo River, South Asia in Peninsula Malacca, Malaysia, and the islands of Sonde, Sumatera, Java, Kalimantan, among others. Park et al.(2020), sustain that the fast-growing tropical species such as Eucalyptus species used to produce energy have a reduced life cycle up to 15-35 years. Only about 25-45\% of the harvested wood is considered good quality raw material for processing in timber, veneer, furniture, parquet, the difference being classified as wood residues (Park et al. 2020). A number of studies have been carried out on tropical wood biomass as potential source for energy. The possibility of using sawdust as domestic wood fuel and bio-oil production from six tropical wood species was evaluated by Numes et al. (2020). Other research (Acuña-Alegria et al. 2018) was done on a number of tropical wood species to investigate the combustion properties and pyrolysis products. The densification technology at room temperature using low compacting pressure (10 -50 MPa) was applied by Acuña-Alegria et al. (2018) to examine the density and compressive strength of fuel briquettes. The same 
research indicated that the fuel properties of sawdust of tropical hardwood species could be significantly enhanced through the application of densification technology at room temperature $\left(28^{\circ} \mathrm{C}\right)$ using low compacting pressure.

Biomass combustion is a complex process defined by chemical reactions by which carbon is oxidized to carbon dioxide, and hydrogen is oxidized to water (Equation 1). Its performance depends on some biomass properties such as moisture content, ash content, volatile matter content, chemical composition, calorific value, bulk density, etc.

$$
\left(\mathrm{C}_{x} \mathrm{H}_{y} \mathrm{O}_{z}\right)+\mathrm{O}_{2}=\mathrm{CO}_{2}+\mathrm{H}_{2} \mathrm{O}+\text { heat }+ \text { ash }
$$

The calorific value is one of the most important characteristics of a fuel and it is defined as the quantity of heat released during the complete combustion of unit mass of biomass. There are two types of calorific value i.e. high calorific value (HCV) or gross calorific value (GCV) which takes into account the latent heat of vaporization of water, which is not included in the low calorific value (LCV) or net calorific value (NCV). $\mathrm{LCV}$ at constant pressure is usually used in combustion calculus and its determination helps to evaluate the potential of fire generated and propagated (Tsai et al. 2020). The high calorific value (HCV) of combustion is obtained directly from a bomb calorimeter tests. The water vapors produced by oxidation of hydrogen are condensed and cooled to the temperature of the bomb releasing about $600 \mathrm{kcal}$ for each kilogram of condensed water vapor, and usually are escaped as steam in the flue gases of stoves and furnaces. The calorific value is different for combustible materials depending on the fuel characteristics, and ranging between $8600-43962$ $\mathrm{kJ} / \mathrm{kg}$ as can be seen in Figure 3.

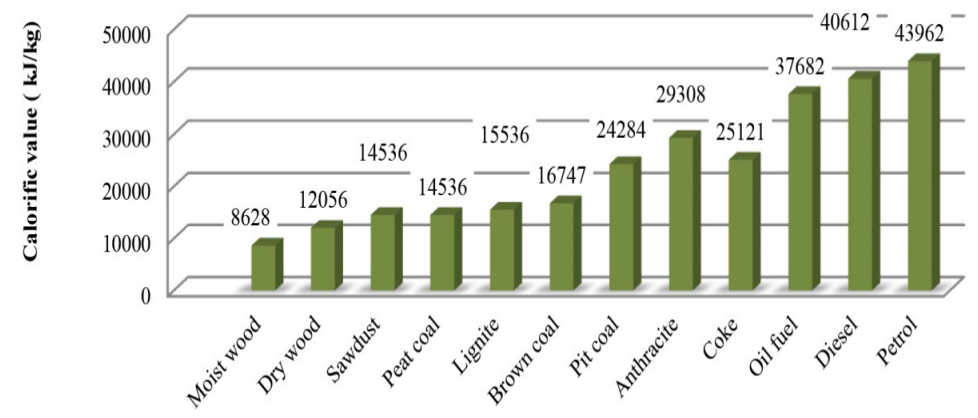

Figure 3: Calorific value of some combustible materials (AEBIOM 2019).

The main objective of this paper was to evaluate the suitability of using biomass wastes from some tropical wood species as solid fuel. The combustion parameters such as calorific value, calorific density, energy release rate, yield combustion and ash content were investigated. The comparative analyze of biomass calorific properties are performed to emphasize that tropical wood waste can successfully be used for renewable energy production replacing the traditional and pollutant coal.

\section{MATERIALS AND METHODS}

\section{Raw material (tropical wood wastes)}

Wastes such as log ends were provided by a veneer factory from Equatorial Africa (i.e. Angola): Acajou (Swietenia mahagoni) Afromosia (Pericopsi selata), Abanos (Diospyros ebenum), Mansonia (Mansonia 
altissima), Iroko (Chlorophora excelsa), Bose (Guarea cedrata), Rose tree (Rosa beggeriana), and Guaiac (Guaiaccum sanctum). The length of log ends varied from 15 to $25 \mathrm{~cm}$ with diameter ranging between 20-40 $\mathrm{cm}$.

\section{Sampling}

The calorific parameters were evaluated on two types of specimens: 10 samples of chips/chops and sawdust less than $1 \mathrm{~g}$ obtained by splitting with circular machine of log ends; 20 pellets obtained from the sawdust resulted at splitting of the log ends.

Ten specimens of $25 \times 25 \mathrm{~mm}$ were used to determine the density according to EN 323 standard (Acuña-Alegria et al. 2018). The specimens used for tests were conditioned until they reached an average moisture content of $10 \%$ for all wood species. Ten other samples (for moisture content influence on calorific value) were conditioned in order to obtain $20 \%$ and $50 \%$ moisture content.

\section{Calorific value}

The calorific properties analysis included the determination of the following parameters: calorific value, calorific density, heat release rate, combustion yield, forestry calorific capacity and ash content. Determination of calorific value for wood and other lignocellulosic materials is similar to that of coal (as solid fuel) and is based on ASTM D3865-12 (2000) and/or DIN 51900-1 (2000). There are not significant differences when other types of fuels as petrol, gasoline, among others are tested.

An oxygen bomb calorimeter (model XRY -1C Shanghai Changji Geological Instrument Co. Ltd., China) with explosive burning process in excess of oxygen at a pressure of 30 bars was used for the experimental tests. The principle operation of the calorimeter is based on measuring the heat released from the complete combustion of a fuel in an oxygen environment (using the Regnault-Pfaundler method). The scheme of calorimeter bomb used in experimental tests is shown in Figure 4. Test contains three distinguished periods: fore, main and after, as can be seen in Figure 4b. In the same figure it can also see the temperature increase from beginning to the end of the test.

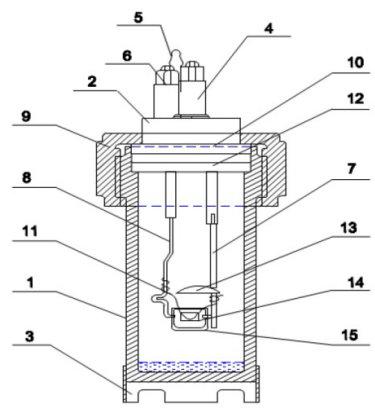

(a)

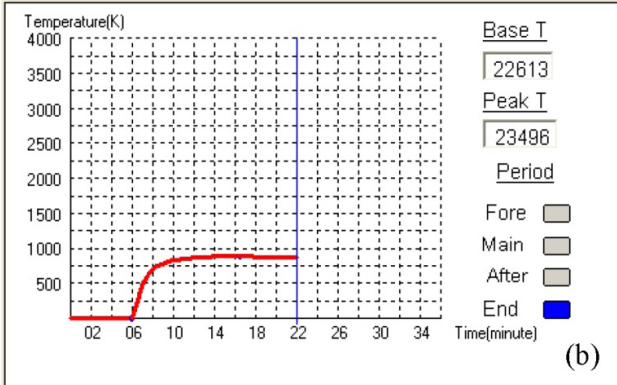

Figure 4: Scheme of calorimeter bomb: a-bomb; b- evolution of temperature inside the bomb calorimeter on each stage of combustion: 1 - main body of the bomb; 2 - cover lid; 3 -support; 4 -oxygen valve; 5 exhaust gas valve; 6- electrode; 7 - connection tube; 8- rod; 9 - cap screw; 10-12 gaskets; 11 -ignition wire; 13-screen protector; 14-wood sample; 15-crucible.

The instrument was calibrated with $1 \mathrm{~g}$ pill of benzoic acid $\left(\mathrm{C}_{6} \mathrm{H}_{5} \mathrm{COOH}\right)$ and determinate the calorimetric coefficient $\mathrm{k}$ (same as see in the Equation 2), knowing the calorific value of benzoic acid of $26463 \mathrm{~kJ} / \mathrm{kg}$ (DIN 51900-1 (2000)).

$$
C V=\frac{k \cdot\left(t_{f}-t_{i}\right)-q_{s}}{m}(M J / k g)
$$


Where:

$\mathrm{k}$ is calorimeter constant (the calorimeter heat capacity), expressed in $\mathrm{MJ} /{ }^{\circ} \mathrm{C} ; \mathrm{t}_{\mathrm{f}}, \mathrm{t}_{\mathrm{i}}$ - the final and initial temperature, in ${ }^{\circ} \mathrm{C} ; \mathrm{m}$ - mass of sample, in $\mathrm{g} ; \mathrm{q}_{\mathrm{s}}$ - heat released by cotton and nickel thread in $\mathrm{MJ} / \mathrm{kg}$.

Because the moisture content is one of the main factors that influence the calorific value, a dependence relationship for $0 \%$ and a certain $\mathrm{M}_{\mathrm{c}}$ value (AEBIOM 2019) can be add (Equation 3):

$$
N C V_{M c}=\frac{C V\left(100-M_{c}\right)-2,44 M_{c}}{100}(M J / k g)
$$

Where: CV- calorific value, for $0 \%$ moisture content, in $\mathrm{MJ} / \mathrm{kg} ; \mathrm{M}_{\mathrm{c}}$-moisture content, in $\%$.

\section{Other calorific features}

Based on of HCV and LCV obtained from calorimeter, the calorific value of the material for $0 \%$ moisture content and other properties such as calorific density, rate of energy release, energetically efficiency and forest calorific capacity were calculated using Equation 4, Equation 5, Equation 6, Equation 7, Equation 8 and Equation 9. There are two types of calorific density, related to the moisture content of analyzed samples.

$$
\begin{aligned}
& C D=C V x \rho_{0} \quad\left(M J / m^{3}\right) \\
& C D_{M C}=L C V x \rho_{M C} \quad\left(M J / m^{3}\right)
\end{aligned}
$$

Where: $\mathrm{CD}, \mathrm{CD}_{\mathrm{MC}}-$ calorific density at oven drywood basis and different $\mathrm{MC}$, respectively; $\mathrm{CV}_{0}=\mathrm{HCV}_{0}$ high calorific value at oven dry basis $(\mathrm{MC}=0 \%)$; LCV- lower calorific value, $\mathrm{MC}$ - moisture content of wood samples, $\% ; \rho_{0}, \rho_{\mathrm{MC}}$ - density of sample at ovendry basis and different $\mathrm{MC}, \mathrm{kg} / \mathrm{m}^{3}$.

Rate of energy release was determined taking into account the calorific value (dry basis) and the sample combustion rate (depending on the mass sample and time of combustion), using the following Equation 6:

$$
R E R=\frac{C V}{t} x m_{0} \quad(k J / \mathrm{min})
$$

Where:

RER- rate of energy release $(\mathrm{KJ} / \mathrm{min})$; $\mathrm{CV}$ - calorific value, expressed on dry basis, $\mathrm{KJ} / \mathrm{kg} ; \mathrm{m}_{0}$ - oven dry mass of sample, $\mathrm{g}$; $\mathrm{t}$ - the combustion time for each sample, min.

Because the usually $\mathrm{MC}$ was $10 \%$, there were used a derivation equation to obtain oven dry mass of samples $\left(\mathrm{m}_{0}\right)$ taking into consideration the mass at a certain moisture content MC (Equation 7):

$$
m_{0}=\frac{m_{M C}}{M C+100} \times 100
$$

Calorific efficiency takes into consideration the influence of moisture content on the calorific value and was determined with Equation 8:

$$
\eta=\frac{L C V_{M c}}{C V} \times 100
$$


Where: $\mathrm{LCV}_{\mathrm{Mc}}$ - low calorific value of samples at a certain moisture content, in $\mathrm{kJ} / \mathrm{kg} ; \mathrm{CV}$-high calorific value (dry basis) of samples, in $\mathrm{kJ} / \mathrm{kg}$;

Even if they are not fast-growing species in the true sense of the word, tropical species have a reduced life cycle of about 70-80 years; they can only be grown for fuel for only 30-40 years, like any energetically species (Salix viminalis, Mischantus gigantea, Populus euroamericana etc.). Therefore, the potential for expansion as bioenergy crops of tropical wood species was evaluated based on the forestry calorific capacity using Equation 9:

$$
F C C=C V \times F C \quad(M J / \text { year } / h a)
$$

Where: FCC-forest calorific capacity, in MJ/year/ha; CV-calorific value of oven dry wooden specie, in MJ/ $\mathrm{kg}$; FC-forestry capacity, in $\mathrm{t} / \mathrm{ha} \cdot$ year.

\section{Ash content}

In order to test the ash content, the fine sawdust, sort by the sieve of $1 \times 1 \mathrm{~mm}$, were used. Some chromium-nickel crucibles were used for tests, with great resistance at high temperatures, clean, dried and burnt to the constant mass. The ash content of the samples was mainly determined based on ASTM D2866-11- 2011 (with small additions from ASTM D-1102-1984, ISO 1928-2009 and ASTM E1755-01 2003) as residue obtained after calcination of fine saw dust samples.1,5-2 grams of the fine sawdust from each tropical wood species were placed in crucible and were dried at $150{ }^{\circ} \mathrm{C}$ for 2 hours (EN 14774-1 2009). Then they were cooled in the desiccators to room temperature and were weighted determining thus the initial mass. The crucible is introduced inside a muffle furnace at a temperature of $650{ }^{\circ} \mathrm{C}$ about 3 hours, enough for a complete calcination, visible by the absence of sparks in the burned ash sample (a mass difference of less than $\pm 0,5 \%$ ), Then the crucibles was removed from the oven, cooled to room temperature in desiccators and weighed on a precision digital balance (accuracy $0,001 \mathrm{~g}$ ), resulting the final mass. The ash content was calculated based on the following Equation 10 .

$$
A_{c}=\frac{m_{s i}-m_{c}}{m_{s f}-m_{c}} \times 100
$$

Where: $\mathrm{m}_{\mathrm{si}}$ - the initial weight of oven dried sample with the crucible, in $\mathrm{g} ; \mathrm{m}_{\mathrm{c}}$ - the weight of empty crucible, in $\mathrm{g} ; \mathrm{m}_{\mathrm{sf}}$ - the final weight of incineration residue with the crucible, in $\mathrm{g}$.

\section{Data analysis}

From each tropical wood species 10 replicates were made. All the values obtained were processed in Excel ${ }^{\mathrm{TM}}$ Microsoft in order to evaluate the differences between species, trend (arithmetic mean) and variations (standard deviation and limits) of the determined parameters. Only values whose limits were within $\pm 5 \%$ of the central value were validated and taken into account in the statistical analysis. Also, only values whose variance coefficient $\mathrm{R}^{2}$ reached a value above 0,9 were validated.

\section{RESULTS AND DISCUSSION}

\section{Results}

\section{About combustion parameters}

The calorimeter given high calorific value and low calorific value of each sample. All values obtained for solid wood pieces were similar to those obtained for pellets of the same species. The average High and Low Calorific Values for all tested specimens, in ascending order, are shown in Figure 5. LCV values ranged from 18456 up to $20720 \mathrm{~kJ} / \mathrm{kg}$. They were slightly lower than the HCV values which varied between 18929 and $21221 \mathrm{~kJ} / \mathrm{kg}$ (Figure 5). 


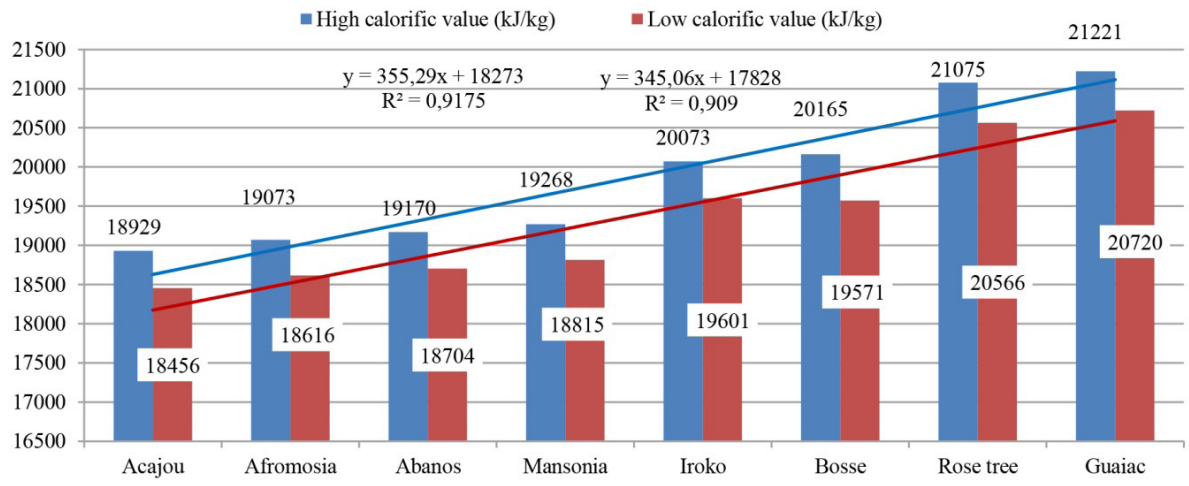

Figure 5: Calorific value of some tropical wood species.

Then, on the base of physical properties (moisture content, mass and density) and calorific value, other combustion characteristics including the calorific density (CD), rate of energy release (RER), combustion yield/efficiency $(\eta)$ and time of combustion of all species tested are presented in Table 1. In order to evaluate the influence of moisture content to $\mathrm{HCV}$, samples from each tropical species were also conditioned in laboratory until they reached the moisture content of $10 \%, 20 \%$ and $50 \%$.

Table 1: Other calorific features of some tropical species.

\begin{tabular}{|c|c|c|c|c|c|c|c|}
\hline Species & $\begin{array}{l}\text { MC } \\
(\%)\end{array}$ & $\begin{array}{c}\text { Mass } \\
(\mathrm{g})\end{array}$ & $\begin{array}{l}\text { Time } \\
\text { (min) }\end{array}$ & $\underset{\left(\mathrm{kg} / \mathrm{m}^{3}\right)}{\rho}$ & $\begin{array}{c}\mathrm{CD}^{\mathbf{a}} \\
\left(\mathbf{M J} / \mathbf{m}^{3}\right)\end{array}$ & $\begin{array}{c}\text { RER }^{\mathrm{b}} \\
(\mathrm{kJ} / \mathrm{min})\end{array}$ & $\begin{array}{c}\eta^{c} \\
(\%)\end{array}$ \\
\hline \multirow[t]{4}{*}{ Bose } & 0 & 0,6600 & 24 & 600 & \multirow{4}{*}{11143} & \multirow{4}{*}{510} & 100 \\
\hline & 10 & 0,6710 & 26 & 610 & & & 92 \\
\hline & 20 & 0,7848 & 26 & 713 & & & 79 \\
\hline & 50 & 1,0110 & 32 & 919 & & & 43 \\
\hline \multirow[t]{4}{*}{ Mansonia } & 0 & 0,5900 & 26 & 536 & \multirow{4}{*}{10084} & \multirow{4}{*}{426} & 100 \\
\hline & 10 & 0,8646 & 29 & 786 & & & 90 \\
\hline & 20 & 0,9984 & 31 & 907 & & & 79 \\
\hline & 50 & 1,2615 & 36 & 1146 & & & 48 \\
\hline \multirow[t]{4}{*}{ Rose tree } & 0 & 0,6000 & 32 & 545 & \multirow{4}{*}{11208} & \multirow{4}{*}{385} & 100 \\
\hline & 10 & 0,6820 & 27 & 620 & & & 90 \\
\hline & 20 & 0,8076 & 29 & 734 & & & 79 \\
\hline & 50 & 1,2510 & 31 & 1137 & & & 48 \\
\hline
\end{tabular}

${ }^{\mathrm{a}}$ Equation 4, Equation 5, ${ }^{\mathrm{b}}$ Equation 6, ${ }^{\mathrm{c}}$ Equation 8.

\section{About moisture content influence on the calorific values (HCV and LCV)}

The solid fuels contain some moisture as free water in large pores and bound water inside of cell wall. Solid wood fuel suppliers require average moisture content below 20\% for firewood (Marafon et al. 2019, Yan et al. 2018) and 10-12\% for other wood fuel products like pellets, briquettes, chips, sawdust, etc. 

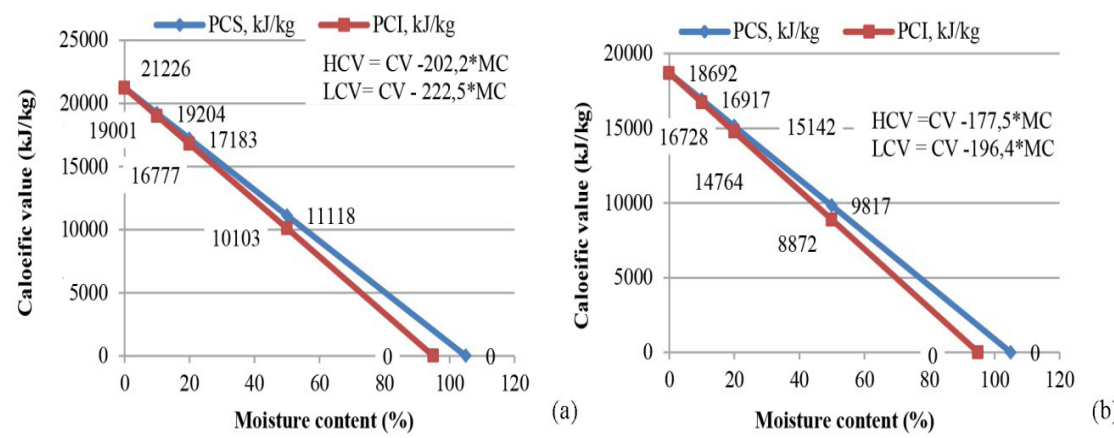

Figure 6: Correlation between the calorific value and the moisture content of two tropical wood species: a-Acajou, b-Guaiac.

The dependency of the calorific power on the sample moisture content was evaluated for the low and high calorific value obtained for Acajou and Guaiac, respectively (Figure 6). Two values of samples moisture content was considered (10\% and $20 \%$ ) to obtain the lineal equations (Table 2), underlining the negative impact of moisture content on the combustion efficiency, particularly on the calorific values.

Table 2: Lineal equations of MC influence on calorific value.

\begin{tabular}{|c|c|c|c|c|c|}
\hline \multicolumn{2}{|c|}{ Specie } & Points in xy plane & Linear equation & $\begin{array}{c}\text { CV } \\
\text { value }\end{array}$ & $\begin{array}{c}\text { Limitative } \\
\text { MC (\%) }\end{array}$ \\
\hline \multirow{2}{*}{ Acajou } & HCV & $(10 ; 16917)(20 ; 15142)$ & HCV $=18692-177,5 * \mathrm{MC}$ & \multirow{2}{*}{18692} & 105,3 \\
\cline { 2 - 4 } & LCV & $(10 ; 16728)(20 ; 14764)$ & LCV $=18692-196,4 * \mathrm{MC}$ & & 95,1 \\
\hline Guaiac & HCV & $(10 ; 19204)(20 ; 17183)$ & HCV $=21226-202,2 * \mathrm{MC}$ & \multirow{2}{*}{21226} & 104,9 \\
\cline { 2 - 4 } & LCV & $(10 ; 19001)(20 ; 16777)$ & $\mathrm{LCV}=21226-222,5 * \mathrm{MC}$ & & 95,3 \\
\hline
\end{tabular}

As it can be seen from Figure 6, the dependence of the calorific value to the initial moisture content of samples is linear and both HCV and LCV decreased drastically with increase in moisture content. The two linear equations could be used for HCV and LCV prediction based on the moisture content of wood fuel specimens, economical thermal calculations, and dimensioning of thermal installations. Intersection with horizontal axis determined the limitative MC.

\section{Referring to other calorific features}

The calorific density (CD) parameter is important knowing that from the denser wood, more heat per unit volume can be obtained at the same moisture content of sample. The values of this parameter ranged from the lowest in Acajou $\left(9892 \mathrm{MJ} / \mathrm{m}^{3}\right)$ to the highest in Guaiac $\left(19090 \mathrm{MJ} / \mathrm{m}^{3}\right)$.

Rate of energy release (RER) differs from a species to another and help to use energy of combustion for stoves (with low rate) or for central heating (with rapidity of energy release). The rate of energy release varied

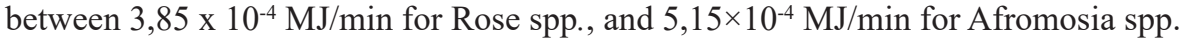

Forestry capacity differs from a forest stand to another, especially because of climacteric conditions. Inside of temperate conditions, the resinous and broad-leaved species has a medium forest capacity of $20 \mathrm{t} / \mathrm{ha} / \mathrm{year}$ $\left(9,6 \mathrm{~m}^{3} / \mathrm{ha} /\right.$ year) dried wood (Ruiz Aquino et al. 2019). 


\section{Referring to ash content}

Ash content is an important parameter of fuel combustion and evaluation, in respect to its disposal and effect on equipment corrosion. Generally, ash content differs from bark to xylem, from juvenile to mature wood, among others (Gao et al. 2019) and is given by the secondary components from wood as oxides, carbonates, etc. Its values ranged from 3,6\% (Guaiac spp.) down to $0,5 \%$ (Rose spp.), with small variation from a specie to another, similar with other values obtained by Gao et al. (2019).

\section{Discussion}

The tested species could be divided in 3 groups based on their calorific potential. Thus, in group A are included the species (Acajou, Afromosia, Abanos and Mansonia) with the lowest calorific values, between $18400 \mathrm{KJ} / \mathrm{kg}$ and $19200 \mathrm{KJ} / \mathrm{kg}$. Group B is represented by Iroko, and Bose species with medium calorific values $19500 \mathrm{KJ} / \mathrm{kg}$ and $21000 \mathrm{KJ} / \mathrm{kg}$ and finally the group C including Rose and Guaiac species with the highest values, around $21000 \mathrm{KJ} / \mathrm{kg}$. The values obtained are comparable with those found by Acuña-Alegria et al. (2018) for Mexican tree species, which are within the range of $17,15 \mathrm{MJ} / \mathrm{kg}$ to $18,61 \mathrm{MJ} / \mathrm{kg}$.

The calorific values of European wood species were in a closer range with values from 18,11 MJ/kg (scot pine) to $19,86 \mathrm{MJ} / \mathrm{kg}$ (Silver fir) (Gao et al. 2019). It can be observed that the average calorific value was with about $11,6 \%$ (with a confidence interval of 95\%) greater than those of European wood species. This can be attributed to the differences in chemical composition. The tropical wood species contain around 43,5\% cellulose, 65,5\% hemicellulose and 30,36\% lignin, as reported by Acuña-Alegria et al. (2018). Their lignin content is considerably higher than of European trees with about 17,6\% which have average cellulose content of $45 \%, 6 \%$ hemicellulose and $25 \%$ lignin (Asibor et al. 2019). The main elemental chemical components of tropical wood species (48,9\% C (carbon), 6,8\% $\mathrm{H}$ (hydrogen) and 44,3\% O (oxygen) might have a positively contribution to the higher calorific value, with about $8,6 \%$ compared to European wood species $(45 \% \mathrm{C}, 6 \% \mathrm{H}$ and $42 \% \mathrm{O})$. The variations of calorific values observed between species are due to the differences in carbon and extractives content especially with phenol compounds in their composition (Ruiz-Aquino et al. 2019). The tropical species as fuel are environmentally friendly alternative to coal, considering that some of them (category $B$ and $C$ ) had the calorific values close to that of the lower coal (Pit coal) $(24284 \mathrm{~kJ} / \mathrm{kg}$ ).

It is observed that the higher wood density (e.g. Guaiac, with $\left.1100 \mathrm{~kg} / \mathrm{m}^{3}\right)$ contributed to an increase of caloric density with about 92,9\% compared to lower density species (Acajou and Abanos). The influence of MC on calorific density is complex demonstrated by the resulting polynomial functions of $4^{\text {th }}$ degree with a correlation coefficient $\mathrm{R}^{2}$ over 0,9 (Figure 7). The results are comparable to the $\mathrm{CD}$ of temperate species briquettes estimated at $9000-24000 \mathrm{MJ} / \mathrm{m}^{3}$ and that of torrefied wood biomass pellets generally about $19-22 \mathrm{MJ} /$ $\mathrm{m}^{3}$ (Asibor et al. 2019).

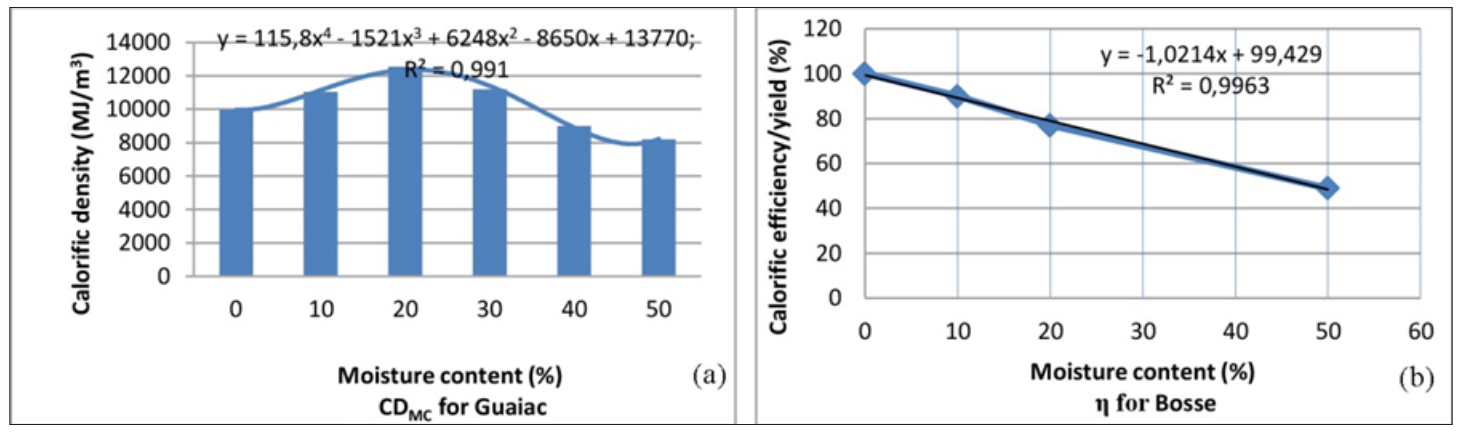

Figure 7:(a) Moisture content influence on calorific density and (b) Moisture content influence on calorific efficiency.

Combustion time and moisture content have influenced the rate of energy release, which increase with decrease in moisture content, due to the shorter time necessary for combustion of dried samples. Lower density and higher inner porosity could lead to a better air circulation in the combustion process increasing the RER, as Acajou spp. has of $4,1 \times 10^{-4} \mathrm{MJ} / \mathrm{min}$. This result agrees with values found by de Freitas Fialho et al. (2019) of $5,5-5,9 \times 10^{-4} \mathrm{MJ} / \mathrm{min}$ in briquettes made of spruce and oak. 
The calorific yield starts from $100 \%$ for a moisture content of $0 \%$ for all tropical specie and decrease down to $50 \%$ for Mansonia or $48 \%$ for Afromosia spp., when moisture content is $50 \%$. This calorific parameter varied from $92 \%$ for Bose spp. down to $88 \%$ for Afromosia spp., at the same moisture content value of $10 \%$. As expected, it decreased dramatically below $45 \%$ with increase in moisture content over $50 \%$ as can be seen in Figure $7 b$.

Lower forest capacity/productivity was reported for oak, less than $3,5-7 \mathrm{t} / \mathrm{ha} /$ year $(2,6-5,2 \mathrm{~m} / \mathrm{ha} /$ year $)$ (Asibor et al. 2019). The tropical wood species can produce more wood per ha reaching 25-30 t/ha/year, thus

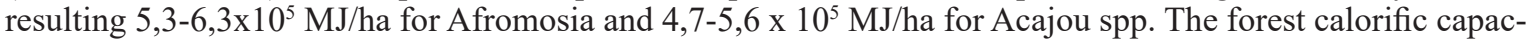
ity of a tropical wood species is with $23-47 \%$ higher than of European beech (Fagus sylvatica) with 3,8 x $10^{5}$ $\mathrm{MJ} / \mathrm{ha}$, as other authors states before (Acuña-Alegria et al. 2018).

The values of ash are higher than of temperate wood species as 0,2-1,2\% (Numes et al. 2020, de Freitas Fialho et al. 2019), but much lower than that of bark with 6-8\% and vegetal waste with $14-18 \%$ (Gao et al. 2019). As ONORM Austrian standard stated, the wood fuel may be considered inadequate when the ash content is above 6\% (Acuña-Alegria et al. 2018).

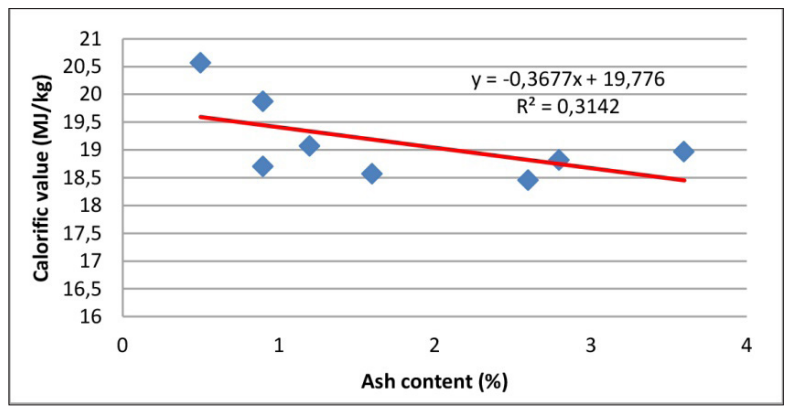

Figure 8: Influence of ash content on calorific value.

Some authors found some correlations between ash content and calorific value, usually negative (AEBIOM 2019). This influence for the studied tropical species is presented in Figure 8. It can observe a slight negative influence, but this cannot be validated because of very low correlation coefficient $R^{2}=0,314$.

\section{CONCLUSIONS}

Beyond the beautiful color and aesthetics of these tropical species that make them apt for veneering and lumber processing, the paper also highlights superior calorific characteristics. The main conclusions that may be drawn from this research on combustion of wastes from some studied tropical wood species are presented below:

The tropical wood species are found to produce higher LCV and HCV (ranging from 18456-20720 kJ/kg and $18929-21075 \mathrm{~kJ} / \mathrm{kg}$, respectively) with $11 \%$ more than temperate wood species, due to their higher lignin content.

The most energetic species was found to be Rose spp. with a calorific value of $20566 \mathrm{~kJ} / \mathrm{kg}$ and $0,5 \%$ ash content, followed by Iroko spp. which exhibit $19873 \mathrm{~kJ} / \mathrm{kg}$ calorific value and 0,9\% ash content.

Moisture content had a significant effect on the combustion parameters, decreasing the calorific value and combustion yield with about $50 \%$ at $\mathrm{MC}$ greater than $40 \%$.

The better ash content was found as $0,5 \%$ in Rose spp., with small variation between species. All values of ash content are convenient, lower than bark or vegetal wastes, which had a positive impact on their high calorific values and calorific yield /efficiency.

The calorific forest capacity of 4,7-5,6 x105 MJ/ha year for Acajou spp., is higher than for majority of 
temperate species, including European beech (Fagus sylvatica).

The calorific characteristic of wastes from selected tropical wood species showed that they have good potential as solid fuel, contributing to an efficient use of residues from furniture, veneers and timber processing. Therefore, it is recommended for the industry to use, besides sawmill or veneer factory, a line for collecting wastes and use them as fire wood or procesed by briquetting or pelletizing. In this way, the resulting remains would be judicious use.

\section{REFERENCES}

Acuña-Alegria, L.; Salinas-Lira, C.; Sepulveda-Villarroel, V.; Vasco-Calle, D.; Ananías, R.A. 2018. Inverse determination of thermal conductivity in wood of Pinus radiata. Maderas-Cienc Tecnol 20(4): 595610. https://doi.org/10.4067/S0718-221X2018005004701.

Adam, A.B.; H. Basta, A.; El-Saied, H.2018. Evaluation of palm fiber components an alternative biomass wastes for medium density fiberboard manufacturing. Maderas-Cienc Tecnol 20(4): 579-594. https://doi. org/10.4067/S0718-221X2018005004601.

AEBIOM. 2019. Statistical Report 2019. European Energy Outlook, European Biomass Association. https://bioenergyeurope.org/statistical-report.html

Asibor, J.; Akhator, E.; Obanor, A. 2019. Energy Potential Study of Some Tropical Wood Species from Nigeria. Current Journal of Applied Science and Technology 37(4): 1-10. https://oi.org/10.9734/cjast/2019/ v37i430295.

ASTM. American Society for Testing and Materials. 2000. Standard Test Method for Gross Calorific Value of Coal and Coke. ASTM D3865-12. 2000. American Society for Testing and Materials: Philadelphia, Pennsylvania.

ASTM. American Society for Testing and Materials. 2003. Standard Method for the Determination of Ash in Biomass. ASTM E1755-01. 2003. American Society for Testing and Materials: Philadelphia, PA

ASTM International. 2011. Standard Test Method for Total Ash Content of Activated Carbon. ASTM D2866-11. 2011. ASTM International: Philadelphia, Pennsylvania.

American Society for Testing and Materials. ASTM. 1984. Standard test method for ash in wood. ASTM D-1102. 1984.American Society for Testing and Materials. Philadelphia, Pennsylvania.

Barros, V.; Melo, A.; Santos, M.; Nogueira, L.; Santos, M.G.2020. Different resource-use strategies of invasive and native woody species from a seasonally dry tropical forest under drought stress and recovery. Plant Physiology and Biochemistry 147: 181-190. https://doi.org/10.1016/j.plaphy.2019.12.018.

DIN. German Institute for Standardization. 2000. Determining the gross calorific value of solid and liquid fuels using the bomb calorimeter, and calculation of net calorific value - Part 1. General information. DIN 51900-1. 2000. German.

European Committee for Standardization. ENN. 2009. Solid biofuels - Determination of moisture content - Oven dry method - Part 1: Total moisture. EN 14774-1. 2009. European Committee for Standardization: Brussels.

Fialho, Lucas de Freitas.; Carneiro, Angélica de Cássia Oliveira.; Carvalho, Ana Marcia Macedo Ladeira.; Figueiró, Clarissa Gusmão.; Silva, Carlos Miguel Simões da.; Magalhães, Mateus Alves.; Peres, Letícia Costa. 2019. Bio-Coal Production With Agroforestry Biomass In Brazil. Maderas-Cienc Tecnol 21(3): 357-366. https://doi.org/10.4067/S0718-221X2019005000308

Gao, K.; Zhang, Z.; Zhu, T.; Tian, X.; Li, T.2019.The influence of leaf removal on tuber yield and fuel characteristics of Helianthus tuberous L. in a semi-arid area. Industrial Crops and Products 131: 8-13. https:// 
doi.org/10.1016/j.indcrop.2019.01.024.

ISO. 2009. Solid Mineral Fuels. Determining the Gross Calorific Power by Calorimeter Bomb and Calculus of Net Calorific Power. ISO 1928. 2009. International Standardization Institute: New York.

Jasinskas, A.;Streikus, D.;Vanzodas, T.2020. Fibrous hemp (Felina 32, USO 31, Finola) and fibrous nettle processing and usage of pressed biofuel for energy purposes. Renewable Energy 149:11-21. DOI.org/10.1016/j.renene.2019.12.007.

Loureiro, B.A.; Sacramento-Vieira, T.; Junqueira-Costa, L.; Barishinikov-Silva, A.; Reis de Assis, M.; Trugilho, F.P.2019. Selection of superior clones of Corymbia hybrids based on wood and charcoal properties. Maderas-Cienc Tecnol 21(4): 619-630. https://doi.org/10.4067/S0718-221X2019005000417.

Marafon, A.C.; Amaral, A.F.C.; de Lemos, E.E.P. 2019.Characterization of bamboo species and other biomasses with potential for thermal energy generation. Pesquisa Agropecuária Tropical 49: e55282. https:// doi.org/10.1590/1983-40632019v4955282

Numes, V.; Silva, R.; Romeiro, G.; Azevedo, D. 2020.The speciation of the organic compounds of slow pyrolysis bio-oils Brasilian tropical seed cake fruits using high-resolution techniques: GCxGC-TOFMS and ESI ( \pm )-Orbitrap HRMS. Microchemical Journal 135: Article 104514. https://doi.org/10.1016/j.microc.2019.104514.

Ozyuguran, A.;Akturk, A.;Yaman, S.2018. Optimal use of condensed parameters of ultimate analysis to predict the calorific value of biomass. Fuel 214:640-646. https://doi.org/10.1016/j.fuel.2017.10.082.

Park, S.; Kim, S.J.; Oh, K.C.; Cho, L.; Kim, D.H. 2020. Investigation of agro-by product pellet properties and improvement in pellet quality through mixing. Energy 190: Article 116380. https://doi.org/10.1016/j. energy.2019.116380.

Perez-Arevalo, J.J.; Velaszquez-Marti, B. 2018. Evaluation of pruning residue of Ficusbenjamiana as a primary biofuel material. Biomass and Bioenergy 108:217-223. https://doi.org/10.1016/j.biombioe.2017.11.017.

Ruiz-Aquino, F.R.; Ruiz-Angel, S.R.; Feria-Reyes, R.F.; Santiago-Garcia, W.S.; Suares-Mota, M.; Rutiaga-Quinones, J. 2019. Wood chemical Composition of Five Tree Species from Oaxaca, Mexico. BioResources 14(4): 9826-9839. https://doi.org/10.15376/biores.14.4.9826-9839.

Tsai, W.T.; Lin, Y.Q.; Tsai, C.H.; Chung, M.H.; Yeh, S.I. 2020.Conversion of water caltrop husk into torrefied biomass by torrefaction. Energy 195: Article 116967. https://doi.org/10.1016/j.energy.2020.116967.

Yan, P.; Xu, L.; He, N. 2018. Variation in the calorific value of different plants organs in China. PloS One 13(6): e0199762. https://doi.org/10.1371/journal.pone.0199762. 